\title{
Successful treatment of bilateral multiple pulmonary arteriovenous malformations in a patient with brain abscess and severe hypoxemia using a combination
} of transcatheter embolotherapy and surgical resection: a case report

\author{
Takahiro Ochi ${ }^{1}$, Masako Chiyo ${ }^{* *}$, Takamasa Ito ${ }^{1}$, Hideharu Furumoto ${ }^{2}$, Toshihiko Sugiura ${ }^{3}$ and Yukio Saitoh ${ }^{1}$
}

\begin{abstract}
Background: A pulmonary arteriovenous malformation is an abnormal dilated blood vessel that makes direct communication between a pulmonary artery and pulmonary vein and can be associated with hypoxemia or neurological complications, including brain abscess and cerebral infarction. Treatment of pulmonary arteriovenous malformation includes surgical resection and transcatheter embolotherapy, however the adaptation of therapies should be considered when a patient is in bad condition.
\end{abstract}

Case presentation: A 51-year-old man was admitted after developing fever, consciousness disorder, and hypoxemia. Magnetic resonance imaging of the brain showed a brain abscess. Bilateral pulmonary arteriovenous malformations were found by contrast computed tomography. Because of a family history of pulmonary arteriovenous malformation, a history of epistaxis, and the existence of oral mucosa telangiectasia, he was diagnosed with hereditary hemorrhagic telangiectasia and brain abscess caused by intrapulmonary right-to-left shunt. The brain abscess improved with antibiotic treatment; however, the administration of oxygen did not ameliorate his hypoxemia. His hypoxemia was exacerbated by positive pressure ventilation. Considering his systemic and respiratory condition, we considered surgery to involve a high degree of risk. After controlling his brain abscess and pneumonia, transcatheter embolotherapy was performed. This improved his systemic condition, enabling surgical treatment.

Conclusions: This middle-aged patient suffering from brain abscess and severe hypoxemia with multiple pulmonary arteriovenous malformations was successfully treated by a combination of transcatheter embolotherapy and surgery. The adaptation and combination of therapies, as well as the sequence of treatments, should be considered depending on the patient status and lesions.

Keywords: Pulmonary arteriovenous malformation (PAVM), Hereditary hemorrhagic telangiectasia (HHT), Surgical treatment, Transcatheter embolotherapy, Brain abscess

${ }^{*}$ Correspondence: chiyo-ths@umin.ac.jp

1 'Department of Thoracic Surgery, National Hospital Organization Chiba

Medical Center, 4-1-2, Tsubakimori, Chuo-ku, Chiba 260-8606, Japan

Full list of author information is available at the end of the article permits use, sharing, adaptation, distribution and reproduction in any medium or format, as long as you give appropriate credit to the original author(s) and the source, provide a link to the Creative Commons licence, and indicate if changes were made. The images or other third party material in this article are included in the article's Creative Commons licence, unless indicated otherwise in a credit line to the material. If material is not included in the article's Creative Commons licence and your intended use is not permitted by statutory regulation or exceeds the permitted use, you will need to obtain permission directly from the copyright holder. To view a copy of this licence, visit http://creativecommons.org/licenses/by/4.0/. The Creative Commons Public Domain Dedication waiver (http://creativecommons.org/publicdomain/zero/1.0/) applies to the data made available in this article, unless otherwise stated in a credit line to the data. 


\section{Introduction}

A pulmonary arteriovenous malformation (PAVM) is an abnormal dilated blood vessel that makes direct communication between a pulmonary artery and pulmonary vein. PAVMs are mainly found in patients with hereditary hemorrhagic telangiectasis (HHT) [1]. Because direct capillary-free communication results in anatomic rightto-left shunt, PAVM can be associated with hypoxemia or neurological complications, including brain abscess and cerebral infarction [1-3]. This report describes the case of a middle-aged patient suffering from a brain abscess, in whom multiple PAVMs were treated by the combination of transcatheter embolotherapy and surgical treatment, which achieved a radical cure that ameliorated hypoxemia and prevented the relapse of neurological complications, after the improvement of the brain abscess by antibiotic treatment.

\section{Case report}

A 51-year-old man presented to the emergency department of our institution with fever, consciousness disorder, and hypoxemia. Magnetic resonance imaging of the brain showed multiple ring-enhancing lesions, which suggested multiple brain abscesses (Fig. 1). Chest roentgenography revealed an abnormal shadow, and contrast computed tomography showed bilateral PAVMs: a $21 \times 13 \mathrm{~mm}$ nodule in the right S1, preceded by a dilated pulmonary artery of $1 \mathrm{~mm}$ in diameter, a $46 \times 34 \mathrm{~mm}$ nodule in the right $\mathrm{S} 3$, preceded by a dilated pulmonary artery of $11 \mathrm{~mm}$ in diameter, and a $28 \times 25 \mathrm{~mm}$ nodule in the left S10, preceded by a dilated pulmonary artery of $1 \mathrm{~mm}$ in diameter (Fig. 2). The transtricuspid pressure gradient was $8.8 \mathrm{mmHg}$ on the basis of the results of the echocardiogram, which did not indicate the presence of pulmonary hypertension. According to the medical consultation after improving the general condition, the patient had been diagnosed with PAVM using chest roentgenography and computed tomography in a medical checkup. In addition, the patient was suffering from exertional dyspnea for a long time period, but he has not received either any follow-up examinations or treatments at his own discretion. Because of the family history of PAVM, the patient's history of epistaxis, and the existence of oral mucosa telangiectasia on a physical examination, in addition to PAVMs, he was diagnosed with HHT [4], and the brain abscess was thought to be caused by intrapulmonary right-to-left shunt.

Thanks to the intravenous administration of antibiotics, the brain abscess resolved, and the neurological symptoms improved; however, his hypoxemia was not ameliorated. Because pneumonia also occurred during the treatment of the brain abscess, the patient was

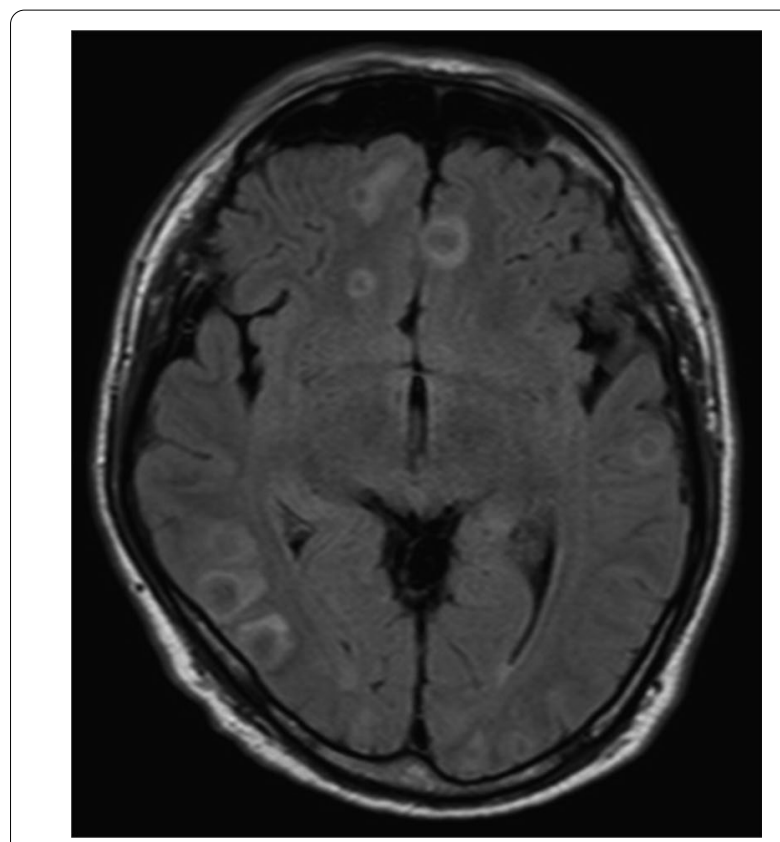

Fig. 1 Enhanced head magnetic resonance imaging revealed multiple ring-enhancing lesions over the cerebrum and cerebellum

intubated and an artificial respirator was used. Despite positive pressure ventilation, his hypoxemia worsened. During pressure-controlled ventilation with driving pressure at $14 \mathrm{cmH}_{2} \mathrm{O}$ and PEEP at $6 \mathrm{cmH}_{2} \mathrm{O}$, breathing $100 \%$ oxygen, an arterial blood gas analysis revealed a partial pressure of arterial oxygen $\left(\mathrm{PaO}_{2}\right)$ of $48.8 \mathrm{mmHg}$. However, changing the ventilator settings (driving pressure at $10 \mathrm{cmH}_{2} \mathrm{O}$ and PEEP at $0 \mathrm{cmH}_{2} \mathrm{O}$ ) improved his oxygenation: $\mathrm{PaO}_{2}$ of $62.8 \mathrm{mmHg}$ while breathing $100 \%$ oxygen. We suspected this was because positive pressure ventilation exacerbated the intrapulmonary right-to-left shunt.

Even after the improvement of pneumonia with the use of additional antibiotics and ventilator weaning, an arterial blood gas analysis revealed $\mathrm{PaO}_{2}$ of $58.7 \mathrm{mmHg}$ while breathing $70 \%$ oxygen. In order to improve his hypoxemia and prevent a relapse of the neurological complications, we planned to treat his PAVMs. We considered that surgical treatment was suitable for the large PAVM in the right S3, due to the safety and certainty of therapy; however, the difficulty in maintaining stable breathing during positive pressure and one-lung ventilation initially prevented us from selecting surgical treatment. Because of the control of the patient's infectious diseases, transcatheter embolotherapy was performed to treat the left PAVM.

The occlusive coils embolized the left PAVM, which was located in S10, resulting in a slight improvement of the patient's hypoxemia. After embolizing the largest PAVM on the right, which was located at S3, the patient's 
a
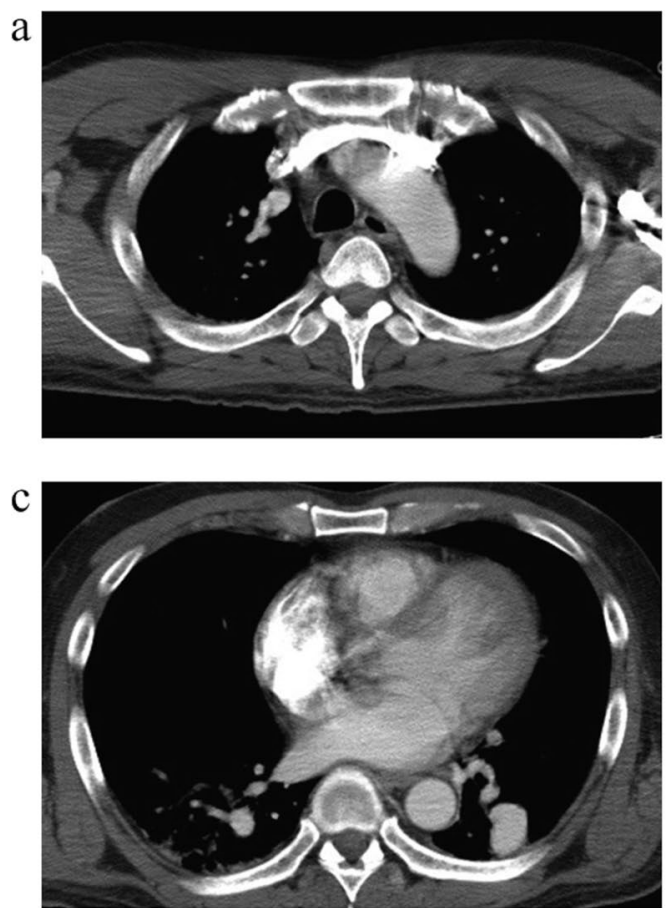

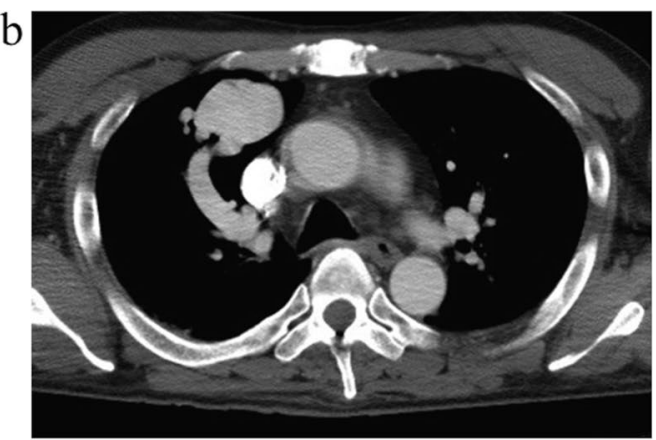

Fig. 2 Enhanced chest computed tomography showed nodular lesions in right S1 (a), S3 (b) and left S10 (c)

a

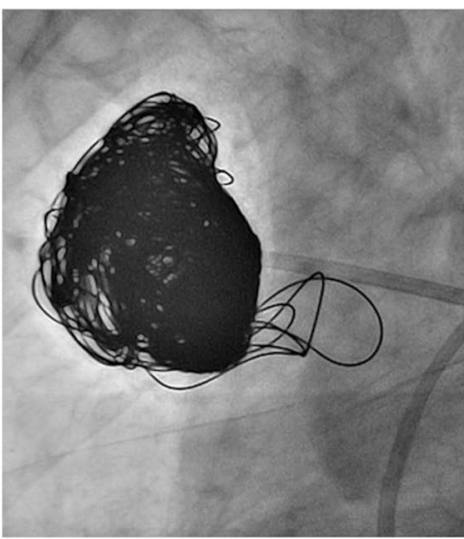

b

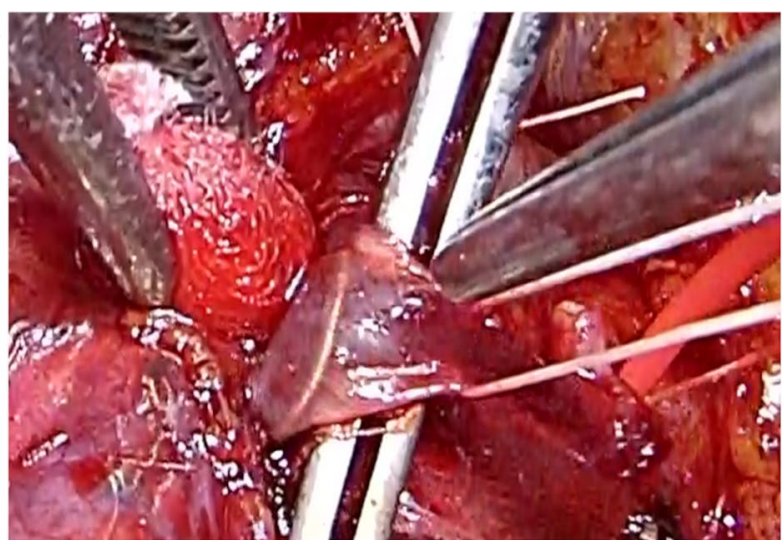

Fig. 3 Arteriography after embolization revealed absence of blood flow in pulmonary arteriovenous malformation in right S3 (a). We confirmed the deviation of coil in the draining vein (b)

oxygenation improved (Fig. 3a). Some occlusive coils protruded from the PAVM in the S3 and reached the V3; however, these coils were so poor in mobility that we left them untouched. After embolotherapy, an arterial blood gas analysis revealed that the $\mathrm{PaO}_{2}$ had improved to $82.7 \mathrm{mmHg}$ while breathing room air. The patient was able to undergo rehabilitation.

Surgical treatment was performed under one-lung ventilation in the left lateral decubitus position. A $20-\mathrm{cm}$ anterolateral skin incision was made along the fourth intercostal space. We confirmed the PAVMs of S1 and S3 and performed right upper lobectomy. In surgery, we found a coil was present in V3 after dissection of the mediastinal pleura and connective tissue. We therefore transected V1, V2, and V3, to avoid cutting or releasing the coil (Fig. 3b). After the transection of V1, V3, and $\mathrm{A} 1+3$, the patient's oxygenation showed a remarkable improvement. 
Transcatheter embolotherapy and surgical treatment were uncomplicated. The patient's $\mathrm{PaO}_{2}$ level while breathing $100 \%$ oxygen increased up to $452 \mathrm{mmHg}$, and his dyspnea was ameliorated. Using pulmonary shunt fraction measurement with the $100 \%$ oxygen method, the shunt fraction was found to have improved from 27.9 to $11.8 \%$. He was discharged to home on the 37 th postoperative day after rehabilitation.

\section{Discussion}

Patients with PAVM can present hypoxemia due to anatomic right-to-left shunt. Since PAVMs may cause lifethreatening complications such as ischemic strokes, cerebral or peripheral abscesses, hemoptysis, and hemothorax, PAVMs of any size should be considered treatment regardless of its size and complications [5]. Because of concern about the recurrence of neurological complications, we aimed to control the patient's PAVMs immediately. However, an examination was required to select the therapeutic strategy, considering the decline in exercise capacity caused by the brain abscess and pneumonia. Treatment of PAVM includes surgical resection and transcatheter embolotherapy. Transcatheter embolotherapy is less invasive and able to preserve the lung function. This treatment could be performed for bilateral or multiple PAVMs; however, it might have been associated with a relatively high recurrence rate and involve risks, such as rupture of a fistula, perforation by the catheter, or embolism of systemic circulation [6, 7]. On the other hand, surgical resection could be more invasive due to the use of general anesthesia, resulting in greater damage to the lung in comparison to transcatheter therapy. However, surgery would offer a chance of curative treatment of the patient's PAVM, irrespective of the size [8]. Because of the decline in exercise capacity, in addition to the existence of bilateral PAVMs, transcatheter embolization, which is a relatively less invasive treatment was considered to be a first choice. However, we judged that the PAVM in the right S3 was so large that surgical resection would be more desirable from the perspective of curability. It is noteworthy that distention in the pulmonary vascular bed caused by positive pressure ventilation could increase the pulmonary vascular resistance and redistribute blood flow in the PAVM, where vascular resistance is relatively small, resulting in the exacerbation of intrapulmonary right-to-left shunt [9-11]. We therefore considered that maintaining stable breathing during positive pressure and one-lung ventilation would be difficult under general anesthesia. Because the patient's infectious diseases were under control, we subsequently dealt with the PAVM in the left lower lobe using transcatheter embolization. In addition, we were able to confirm that embolization of the PAVM in the right S3 reduced the rate of blood flow with intrapulmonary right-to-left shunt and contributed to improving the patient's oxygenation. Transcatheter embolization alone was not sufficient to curatively treat the patient's PAVMs; however, it increased the patient's exercise capacity, enabled him to undergo harder rehabilitation, and facilitated the performance of surgery under general anesthesia. These treatments allowed us to safely perform surgical resection of the PAVMs in the right upper lobe, and allowed the patient to return to his previous life-in fact, he was more comfortable than before treatment. There have been several reports about therapeutic strategies for multiple PAVMs, including surgery and endovascular therapy $[6,12]$; however, combined treatment might be an option. Taken together, the adaptation and combination of therapies, as well as the sequence of treatments, should be considered depending on the patient status and lesions.

\section{Conclusion}

Treatment for PAVM includes surgical resection and transcatheter embolotherapy. We successfully treated a patient with bilateral PAVMs in bad condition using a combination of these treatments. Appropriate treatments should be selected depending on the number and size of lesions and the patient's physical status.

\section{Abbreviations \\ $\mathrm{PaO}_{2}$ : Partial pressure of arterial oxygen; PAVM: Pulmonary arteriovenous malformation; HHT: Hereditary hemorrhagic telangiectasia.}

\section{Acknowledgements}

Not applicable.

\section{Authors' contributions}

TO drafted the manuscript. All authors participated in the treatment. MC, TI, and TS contributed to the development of methodology. All authors read and approved the final manuscript.

Funding

The authors have not declared funding for this study.

Availability of data and materials

Please contact author for data requests.

\section{Declarations}

Ethics approval and consent to participate Not applicable.

\section{Consent for publication}

Informed consent of clinical detail and image publication was obtained from the patient.

\section{Competing interests}

The authors declare that they have no competing interests.

\section{Author details}

${ }^{1}$ Department of Thoracic Surgery, National Hospital Organization Chiba Medical Center, 4-1-2, Tsubakimori, Chuo-ku, Chiba 260-8606, Japan. ${ }^{2}$ Department of Neurology, National Hospital Organization Chiba Medical Center, 4-1-2, 
Tsubakimori, Chuo-ku, Chiba 260-8606, Japan. ${ }^{3}$ Department of Respirology Medicine, Chiba University Graduate School of Medicine, 1-8-1, Inohana, Chuo-ku, Chiba 260-8670, Japan.

Received: 17 December 2020 Accepted: 30 August 2021

Published online: 08 September 2021

\section{References}

1. Swanson KL, Prakash UB, Stanson AW. Pulmonary arteriovenous fistulas: Mayo Clinic experience, 1982-1997. Mayo Clin Proc. 1999;74(7):671-80.

2. Shovlin CL. Pulmonary arteriovenous malformations. Am J Respir Crit Care Med. 2014;190(11):1217-28.

3. Teng P, Li W, Ni Y. Surgical lobectomy of pulmonary arteriovenous malformations in a patient with presentations regarded as sequela of tuberculosis: a case report. J Cardiothorac Surg. 2020;15(1):290.

4. Shovlin CL, Guttmacher AE, Buscarini E, Faughnan ME, Hyland RH, Westermann $C J$, et al. Diagnostic criteria for hereditary hemorrhagic telangiectasia (Rendu-Osler-Weber syndrome). Am J Med Genet. 2000;91(1):66-7.

5. Shovlin CL, Condliffe R, Donaldson JW, Kiely DG, Wort SJ. British Thoracic Society clinical statement on pulmonary arteriovenous malformations. Thorax. 2017;72(12):1154-63.

6. Trerotola SO, Pyeritz RE. PAVM embolization: an update. Am J Roentgenol. 2010;195(4):837-45.
7. White RI Jr, Pollak JS, Wirth JA. Pulmonary arteriovenous malformations: diagnosis and transcatheter embolotherapy. J Vasc Interv Radiol. 1996;7(6):787-804.

8. Hayashi K, Motoishi M, Horimoto K, Sawai S, Hanaoka J. Left upper division segmentectomy with a simultaneous displaced bronchus and pulmonary arteriovenous anomalies: a case report. J Cardiothorac Surg. 2018;13(1):40.

9. Sharma D, Pandia MP, Bithal PK. Anaesthetic managementof Osler-WeberRendu syndrome with coexisting congenital methaemoglobinaemia. Acta Anaesthesiol Scand. 2005;49(9):1391-4.

10. Yeh YL, Liu CK, Chang WK, Chan KH, Li JY, Tsai SK. Detection of right to left shunt by transesophageal echocardiography in a patient with postoperative hypoxemia. J Formos Med Assoc. 2006;105(5):418-21.

11. Friedman BC, McGrath BJ, Williams JF. Pulmonary arteriovenous fistula: mechanical ventilation and hypoxemia. Can J Anaesth. 1992;39(9):963-5.

12. Kohno M, Noda K, Moriyama H, Nishimura Y. Segmental arterial ligation under video-assisted thoracoscopy combined with transcatheter embolotherapy for multiple bilateral pulmonary arteriovenous malformations. Interact Cardiovasc Thorac Surg. 2004;3(4):596-8.

\section{Publisher's Note}

Springer Nature remains neutral with regard to jurisdictional claims in published maps and institutional affiliations.
Ready to submit your research? Choose BMC and benefit from:

- fast, convenient online submission

- thorough peer review by experienced researchers in your field

- rapid publication on acceptance

- support for research data, including large and complex data types

- gold Open Access which fosters wider collaboration and increased citations

- maximum visibility for your research: over $100 \mathrm{M}$ website views per year

At BMC, research is always in progress.

Learn more biomedcentral.com/submissions 